\title{
ISOKINETIC EXTERNAL ROTATION STRENGTH OF SHOULDER: CORRELATION WITH AGE AND MUSCLE SIZE
}

\author{
Pradhan R L*, Itoi E*, Shimizu T*, Wakabayashi I*, Sato K* \\ * Akita University School of Medicine, 1-1-1 Hondo, Akita 010-8543, Japan
}

\section{ABSTRACT}

The purpose of this study was to determine the correlation between quantitative (cross sectional areas) evaluation of the posterior cuff muscles and mechanical strength in asymptomatic shoulders with special reference to aging. The cross-sectional area of the combined infraspinatus and teres minor muscles were measured, in the sagittal oblique magnetic resonance images, in eighty-one patients with a mean age of 44.06 years (range 19 - 74). These areas were correlated with the measured isokinetic strength in external rotation at angular velocities of $60 \mathrm{deg} / \mathrm{s}$ and $180 \mathrm{deg} / \mathrm{s}$ using Cybex 770 NORM. The results show that there was a gradual decrease in size of the muscles as the age of the individual increases. A strong correlation was found between aging and combined cross-sectional area and peak torque as well. The correlation between combined cross-sectional area and peak torques at both angular velocities were less strong. Further, the correlation between the peak torque/cross-sectional area ratio with aging was also less significant, which may imply that the decrease in the muscle strength was greater than the change in muscle area. Our results suggest that there may be other qualitative and biochemical factors that may determine the true strength of the muscles in the aged population.

Key Words: Aging, muscle, cross sectional area, strength, shoulder.

\section{INTRODUCTION}

The strength of a given shoulder action is determined by the net torque created by the muscles responsible for this action. The magnitude of force deliverable by a muscle is determined by its size, health and condition. It is also influenced by the length of the muscle in the specified position of the shoulder - muscles are usually stronger near the middle of their excursion. ${ }^{1}$ Maughan et al..$^{2}$ reported, in normal knee joints of young males that significant relationship exists between quadriceps muscle cross-sectional area (CSA) and the maximum volun- tary isometric force. On the other hand, Overend et al. ${ }^{3}$ found that the correlation of knee extensor and flexor strength with muscle CSA was significant at both velocities in elderly men, but not at either velocities for knee flexors in younger men. The cross-sectional areas (which is related to muscle atrophy) of the shoulder muscles depend on the gender, and/or age for the cuff muscles. ${ }^{4}$ Kallman et al. ${ }^{5}$ reported that grip strength was related with muscle mass, but more strongly so when correlated with age than muscle mass. Frontera et al. ${ }^{6}$ reported that substantial difference in muscle strength with advancing age existed and that muscle mass was a major determinant in age-related dif-

\footnotetext{
Address for correspondence :

Dr. Rabindra L. Pradhan

Kathmandu Medical College, Sinamangal, Kathmandu, Nepal

Email: rabi.ortho@gmail.com
}

Received Date : $8^{\text {th }}$ Aug, 2005

Accepted Date : $2^{\text {nd }}$ Dec, 2005 
ferences and independent of location. Isokinetic muscle testing of shoulder muscles performed in normal volunteers ${ }^{7}$ has shown to be related to aging, but the relationship between the cross-sectional area and the mechanical strength of the muscle has not been addressed. Itoi et al. ${ }^{8}$ have briefly mentioned that shoulder strength may be affected by muscle atrophy. Muscle performance evaluation in the shoulder joint is more complex than the knee joint, where there is only one dominant plane of motion. In the shoulder joint contributions to motion are made by four joints in addition to the spine and ribs with complex interaction. ${ }^{9}$ This complex relationship changes the direction and point of application of muscle force, which in turn influence the torque reproduced by the muscle. We hypothesized that the strength of the muscle would be proportional to its cross-sectional area and that there would be negative correlation between the mechanical strength and aging. Therefore, the purpose of this study was to evaluate the correlation between aging, the cross-sectional area of muscles and isokinetic strength in external rotation in asymptomatic shoulders.

\section{PATIENTS AND METHODS}

Between January 1994 and December 1999, eighty-one shoulders of asymptomatic subjects were enrolled in this study. The subjects were excluded if they had symptoms in the respective shoulder and if the magnetic resonance imaging (MRI) revealed any abnormality in the cuff tendons or the capsuloligamentous configuration. The age of the subjects ranged from nineteen to seventy-one years with a mean of 44.06 years.

\section{Quantitative evaluation of MRI images}

Magnetic resonance imaging was performed on a 1.5-T wholebody MR imager (Signa, GE Medical Systems, Milwaukee, WI). The arm was placed in a dual phased array surface coil- imaging matrix, which is reported to increase the signal-to-noise ratio by virtue of several receiver coils working in concert to receive signal and promote field homogeneity. ${ }^{10}$ The arm was placed at the side of the body in neutral position with the thumb pointing upward. T1-weighted spin echo images (TR/ $\mathrm{TE}=600 / 23 \mathrm{msec}$ ), parallel to the glenohumeral joint, in the oblique sagittal plane were obtained in $3-\mathrm{mm}$ gapless slices with a $10-\mathrm{cm}$ field-of-view and a 256x128 matrix size. The CSA of the combined infraspinatus (ISP) and teres minor (TM) muscles were measured using an image-processing software, NIH Image (National Institutes of Health, Bethesda, USA) at the slice level $10 \mathrm{~mm}$ proximal to the glenoid surface (Figure 1.A). This position was found to be easily reproducible and included the muscular (versus tendinous) parts of the rotator cuff. Regions of interest were determined by the contours of the infraspinatus and teres minor muscles (Figure 1.B). All measurements were done by the same operator throughout the study. To compensate for individual body constitution the measured areas were standardized with the method described by Zanetti et. al. ${ }^{4}$

\section{Isokinetic strength testing}

The isokinetic strength was measured, using Cybex 770 NORM, with the subjects sitting and the elbow flexed to $90^{\circ}$ and the shoulder placed in the so called dependent position, ${ }^{11}$ which allows elevation of the arm to $15^{\circ}$ in the frontal plane for clearance of the brace in external rotation. After the Cybex system was aligned properly to the desired position, the subject's arm and forearm were secured with splints and body stabilized by padded straps across the chest. Range of motion limits was set from $45^{\circ}$ of internal and $45^{\circ}$ of external rotation at angular velocities of $60 \mathrm{deg} / \mathrm{s}$ and $180 \mathrm{deg} / \mathrm{s}$. We asked the subject to begin external rotation from the initial position and to continue forceful external rotation until reaching a point of $45^{\circ}$

Fig. 1(A,B): Measurement in oblique sagittal MRI images at the slice level $10 \mathrm{~mm}$ proximal to the glenoid surface (A) of the combined cross-sectional area of infraspinatus and teres minor muscle (B). 
of external rotation. A preparatory session consisting of three submaximum and two maximum efforts was first performed to accustom the subject. This was followed by five maximum efforts at $60 \mathrm{deg} / \mathrm{s}$ angular velocity. After sufficient rest, averaging two minutes, another session of five maximum efforts at $180 \mathrm{deg} / \mathrm{s}$ were performed.

\section{Analysis of data}

The average of the peak torque recorded by each subject during five maximum isokinetic efforts at a given angular velocity was used as the value of isokinetic peak torque for that angular velocity. This method of calculation of the isokinetic peak torque has been shown to be more reliable that the use of values obtained from single effort. ${ }^{12}$ The peak torque is the highest torque value seen from all repetitions and all points in the range of movement. The data are expressed as mean \pm standard deviation (SD). Means were compared with analysis of variance and the correlation calculated by simple linear regression. The 0.05 level of significance was used to determine significant differences.

\section{RESULTS}

All subjects were able to tolerate isokinetic testing of the strength of external rotation without discomfort. The distribution of combined CSA, torque at $60 \mathrm{deg} / \mathrm{s}$ and $180 \mathrm{deg} / \mathrm{s}$, and peak torque/CSA ratio according to age in decades are presented in Table I. Significant correlation was observed for external rotation peak torque at both velocities $(\mathrm{r}=0.629, \mathrm{p}<0.0001$ and $\mathrm{r}=0.730, \mathrm{p}<0.0001$ ) with aging (Figures $2 \mathrm{~A}, \mathrm{~B}$ ). There was significant correlation when comparing between the combined CSA of the ISP and TM and aging $(r=0.671, p<0.0001)$. (Figure 3) The peak torque measured isokinetically at $60 \mathrm{deg} / \mathrm{s}$ was statistically greater than those measurements obtained at $180 \mathrm{deg} / \mathrm{s}(\mathrm{p}<0.0001)$. The relation between combined CSA of ISP and TM and peak torque at both angular velocities were less strong $(r=0.416, p 0.001, r=0.500, p$ 0.001) (Figures 4 $\mathrm{A}, \mathrm{B})$ Moreover, the peak torque/CSA ratio and aging were less significant when comparing in both the angular velocities $(\mathrm{r}=$ 0.330, p 0.0026, r = 0.510, p 0.001) (Figures $5 \mathrm{~A}, \mathrm{~B}$ ).

\section{Feak toripue 6id deg/s $=26562-175$, age: $\mathrm{I}=.60$}

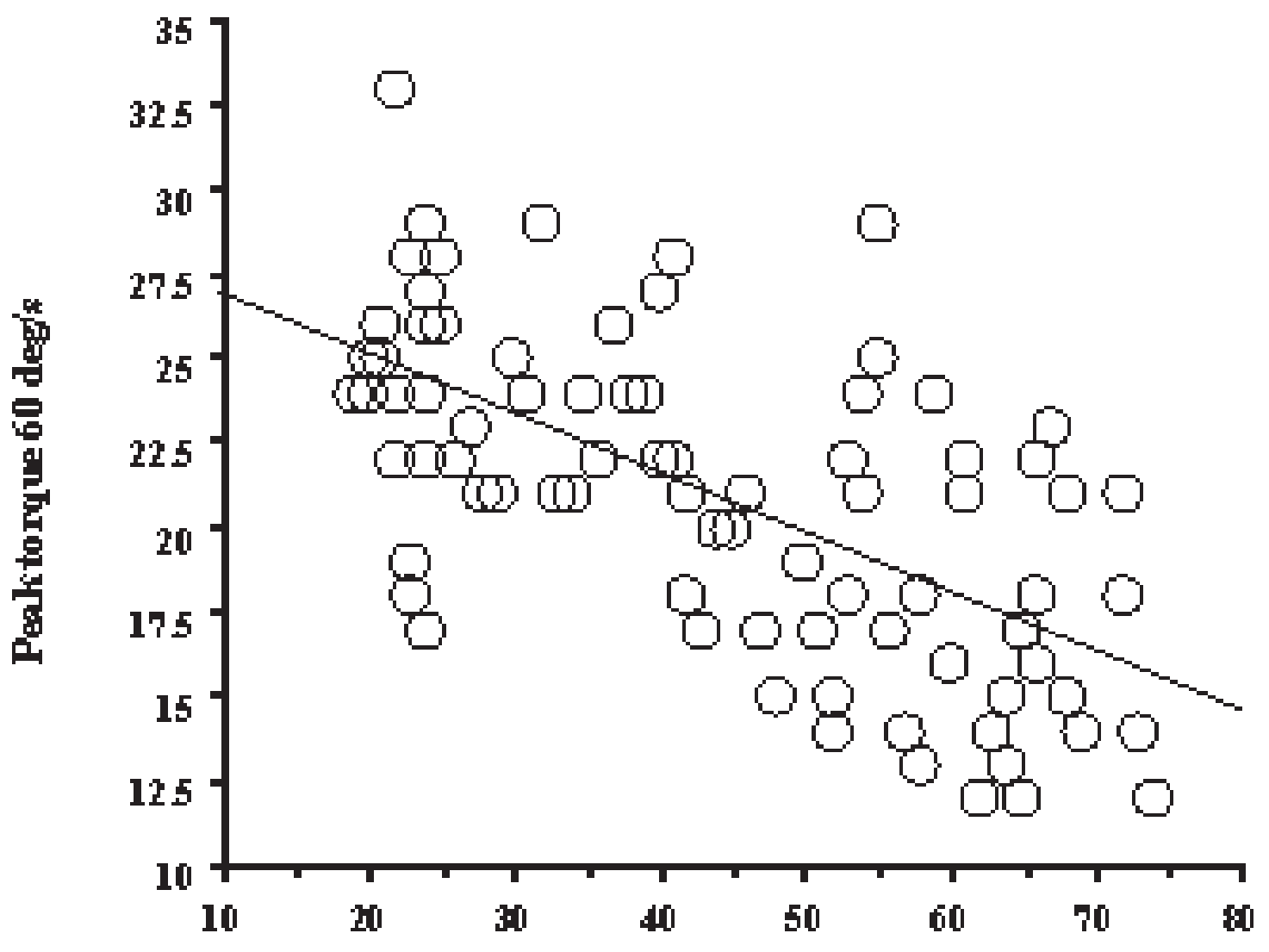

\section{AgP}

Fig. 2(A): Significant correlation was observed for external rotation peak torque at both velocities with aging. (A: $60 \mathrm{deg} / \mathrm{s}$ angular velocity, $\mathrm{r}=\mathbf{0 . 6 2 9}, \mathrm{p}<\mathbf{0 . 0 0 0 1}$ ) 
Table I : Mean values \pm S.D. for peak torque in external rotation at $60 \mathrm{deg} / \mathrm{s}$ and $180 \mathrm{deg} / \mathrm{s}$ and combined cross-sectional area (CSA) for different age groups

\begin{tabular}{|c|c|c|c|c|c|c|c|}
\hline agfGrud & 4 & 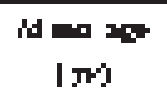 & 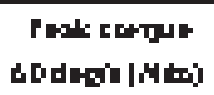 & 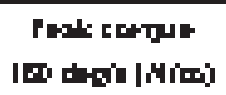 & Ga|c世" & 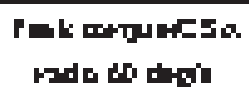 & 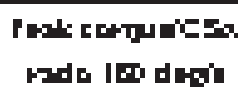 \\
\hline $1 F-11$ & 11 & $11 \mathrm{IT}$ & 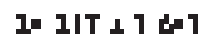 & 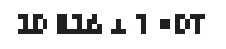 & $-F \Pi+11 T$ & 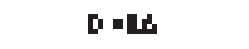 & [ - IL \\
\hline $15-11$ & IE & $11 \leq 5$ & $11 \mathrm{TLO}+1 \leq 4$ & 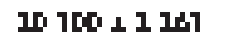 & 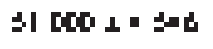 & " & [17 \\
\hline $17--1$ & 11 & -171 & $15 \mathrm{~F} 11+1 \mathrm{LIL}$ & 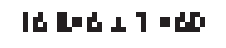 & 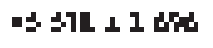 & 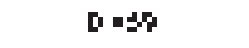 & [1 1 pr \\
\hline$-F- \pm 1$ & I. & \pm-1. & If cto + a dro & 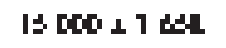 & 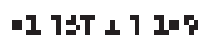 & $5=1$ & [1] \\
\hline Str - d & It & 山EL & 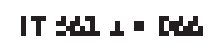 & II - 11 \& 1 I & 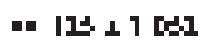 & D 1ra & II \\
\hline $\boldsymbol{H}-\mathbf{T}$ & \pm & T & IS Iro + 1 ג & 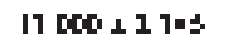 & 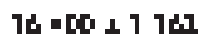 & {$[0.1=$} & [1]T \\
\hline
\end{tabular}

Pealk torque 180 degis $=25.49 \mathrm{~m}-.193$, age $: \mathbf{r}=.730$

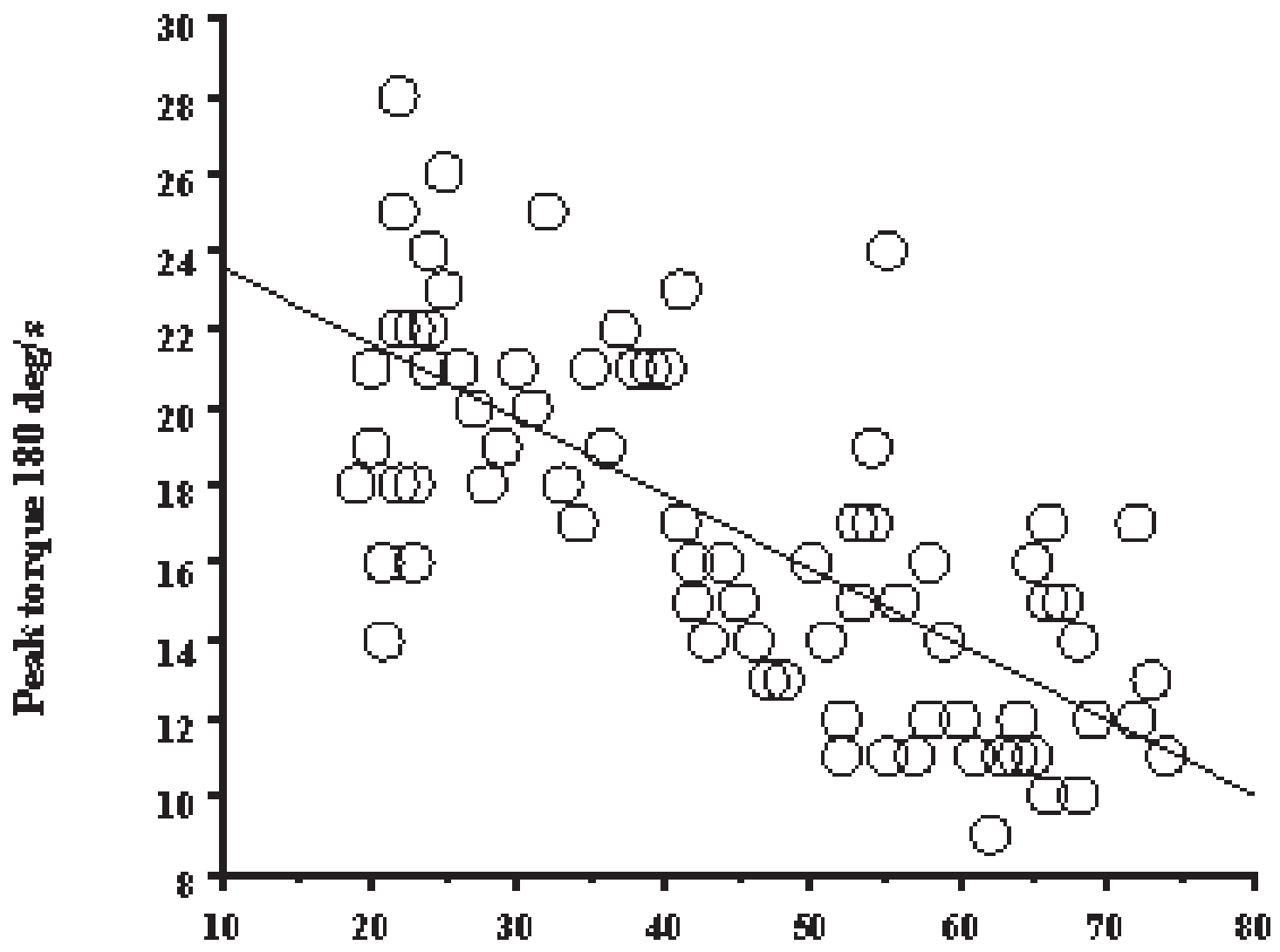

AgF

Fig. 2(B): Significant correlation was observed for external rotation peak torque at both velocities with aging.

(B: $180 \mathrm{deg} / \mathrm{s}$ angular velocity, $\mathrm{r}=\mathbf{0 . 7 3 0}, \mathrm{p}<\mathbf{0 . 0 0 0 1}$ ) 


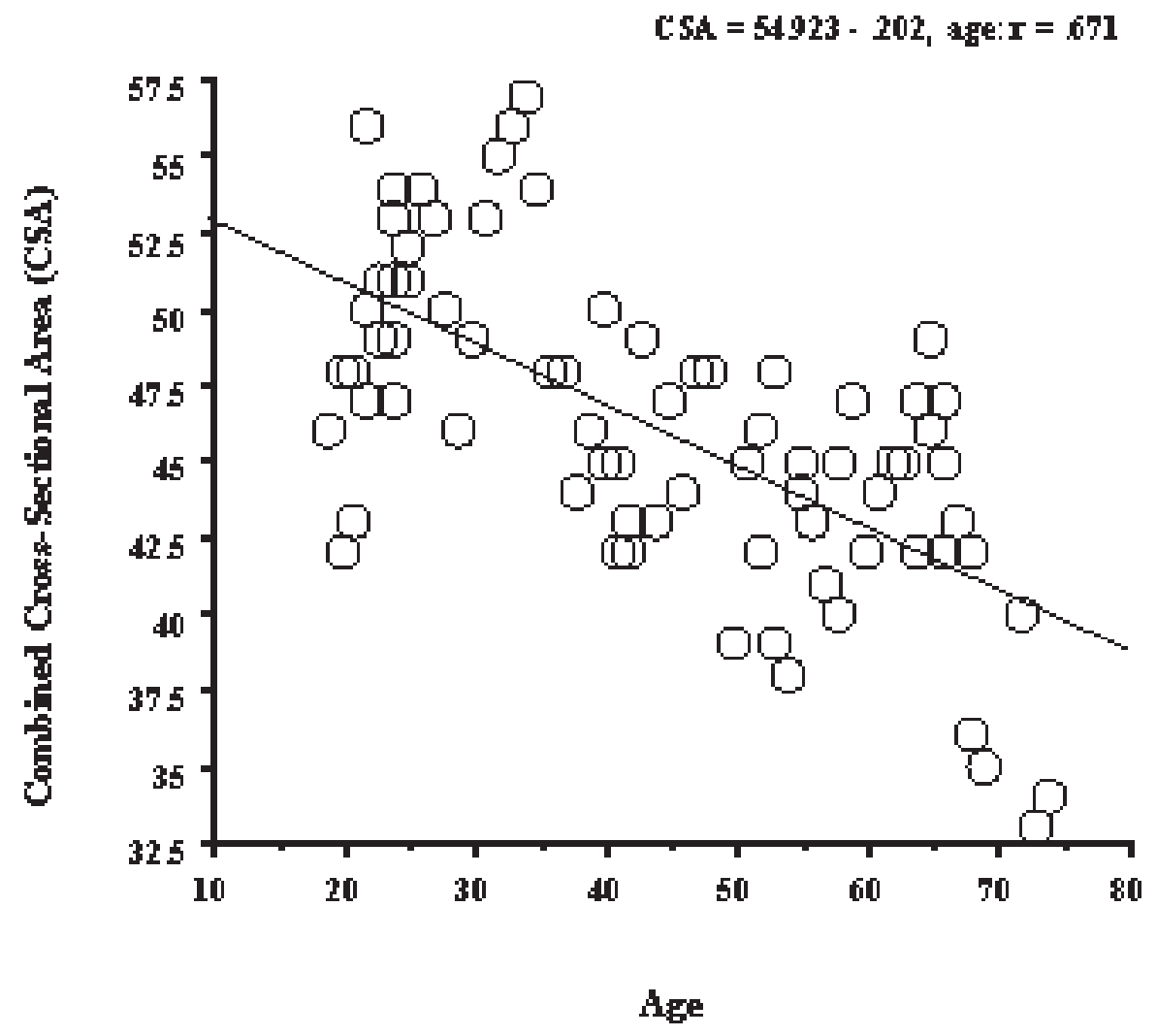

Fig. 3: Significant correlation when comparing between the combined CSA of the ISP and TM and aging $r=0.671, p<0.0001$ )

Peak torque $=3244+.383 \mathrm{CSA}_{1} \mathrm{r}=.46$

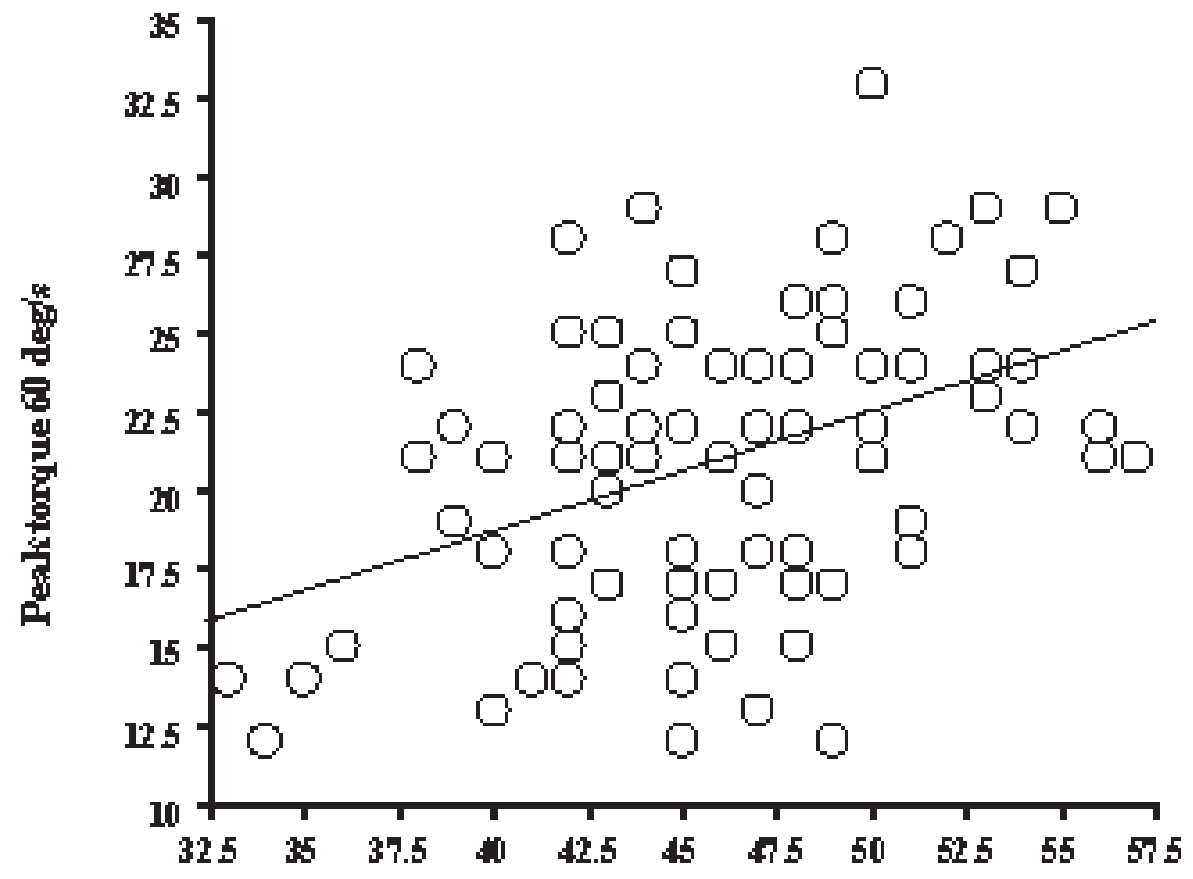

\section{Comb ined Cross-Sectional Area (CSA)}

Fig. 4(A): Correlation between CSA and peak torque at $60 \mathrm{deg} / \mathrm{s}$ was less strong

(A: $60 \mathrm{deg} / \mathrm{s}$ angular velocity, $\mathrm{r}=0.416, \mathrm{p}<0.001$ ) 


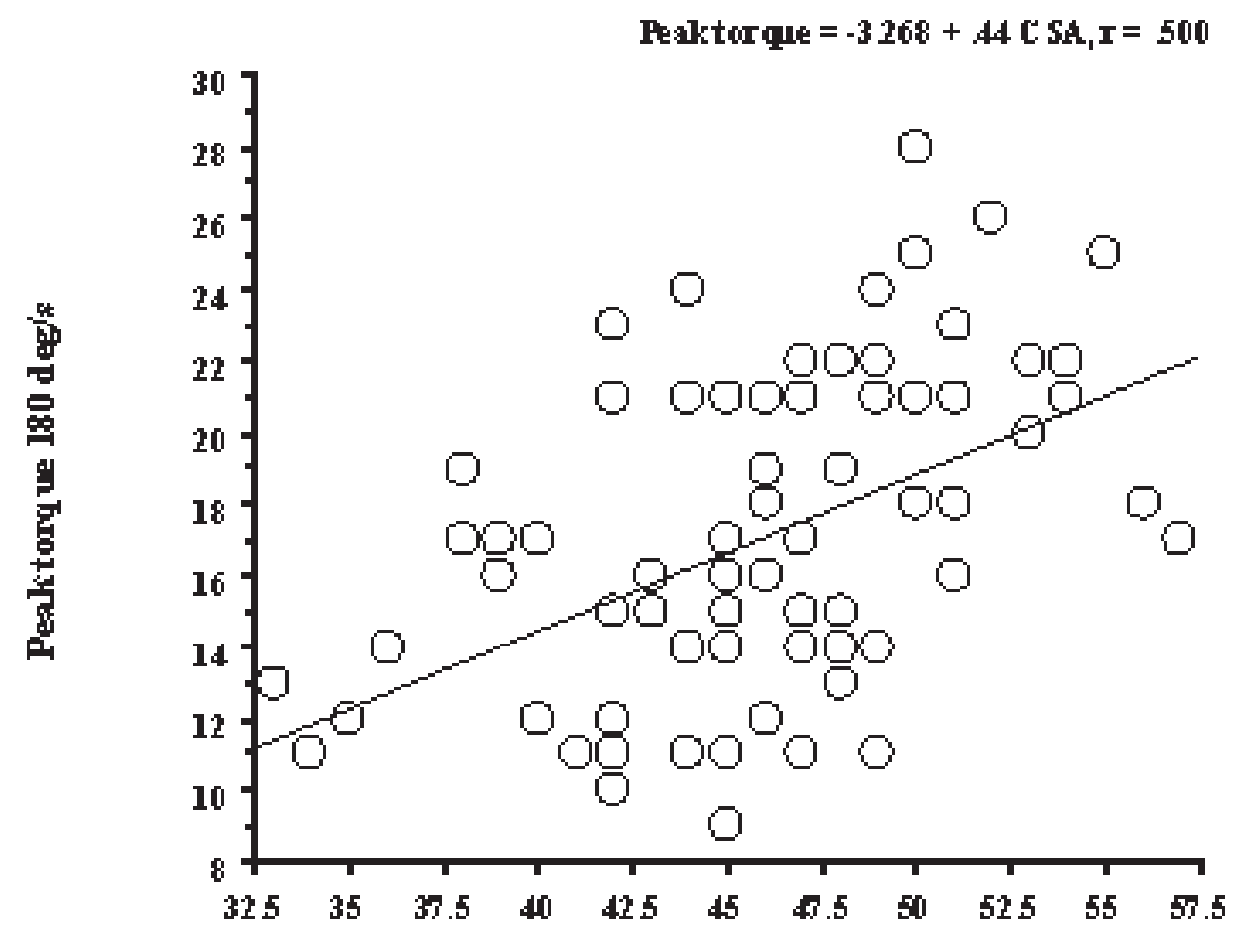

Combined Cross-Sectional Area (CSA)

Fig. 4(B): Correlation between CSA and peak torque at $180 \mathrm{deg} / \mathrm{s}$ was less strong (B: $180 \mathrm{deg} / \mathrm{s}$ angular velocity, $\mathrm{r}=\mathbf{0 . 5 0 0}, \mathrm{p}<\mathbf{0 . 0 0 1}$ )

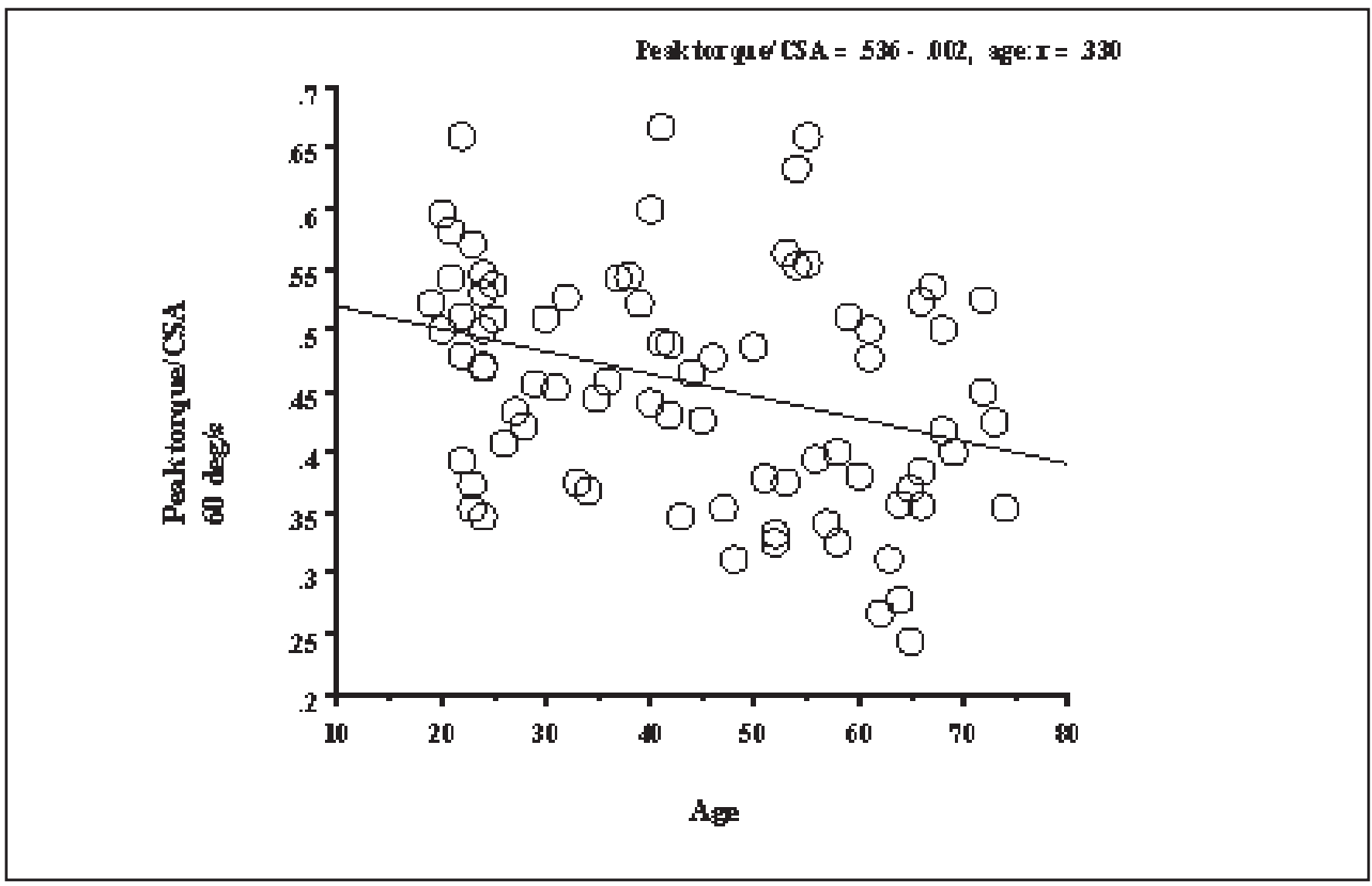

Fig. 5(A): The peak torque / CSA ratio and aging were less significantly correlated in both the angular velocities. (A: $60 \mathrm{deg} / \mathrm{s}$ angular velocity, $\mathrm{r}=\mathbf{0 . 3 3 0}, \mathrm{p}<\mathbf{0 . 0 0 2 6}$ ) 


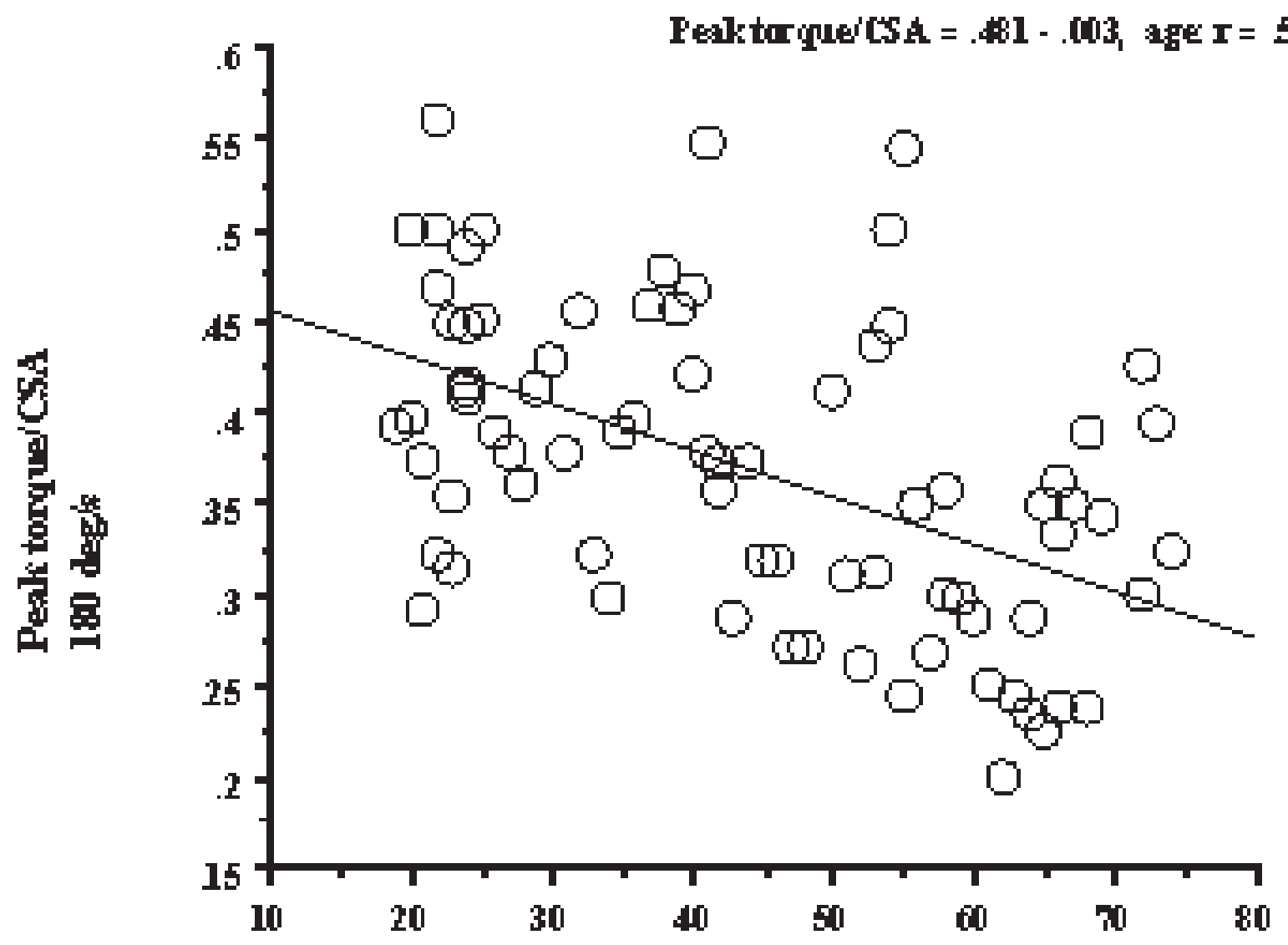

Age

Fig. 5(B): The peak torque / CSA ratio and aging were less significantly correlated in both the angular velocities.

(B: $180 \mathrm{deg} / \mathrm{s}$ angular velocity, $\mathrm{r}=\mathbf{0 . 5 1 0}, \mathrm{p}<0.001$ )

\section{DISCUSSION}

Isokinetic strength is defined as the maximum torque that can be exerted against a preset rate-limiting device. In isokinetic exercise, the patient can activate the largest number of motor units and achieve his or her maximal dynamic loading throughout the entire range of motion. Cybex machine has shown to a reliable method of measuring isokinetic strength and the data reproducible in both pre and postoperative conditions. ${ }^{7,8,13}$ Forces are recorded at set velocities, thus providing objective information regarding shoulder strength. Many different positions have been used to test the external rotation strength of the shoulder. ${ }^{11}$ We chose the dependent position because this was the position where the subjects were most comfortable. Our purpose was not to establish normal values of external rotation torque, but to measure the isokinetic strength in a consistent manner and correlate with aging and the combined cross-sectional areas of ISP and TM.

Our results show that the effect of aging on the isokinetic strength and CSA in external rotators of the shoulder is similar to other parts of the body. ${ }^{3,5}$ We have found that there is an agerelated difference in the combined CSA of the ISP and TM, and between the isokinetic strength and aging. This finding is in agreement with the previous study that has revealed significant differences in external rotation strength in younger and older subjects. ${ }^{7}$ When comparing with the CSA and peak torque, the correlation was lesser than that of aging and CSA. Moreover, in our study, there was less strong correlation between age and the peak torque/CSA ratio both at the $60 \mathrm{deg} / \mathrm{s}$ and 180 $\mathrm{deg} / \mathrm{s}$ angular velocities $(\mathrm{r}=0.330, \mathrm{r}=0.510)$. Kallman et al., ${ }^{5}$ in their grip strength study, also found that grip strength was more strongly correlated with age than muscle mass. Various changes in muscle tissue with age may be accountable for the observed loss of strength in excess of the decline in muscle mass. It is agreed that fast-twitch fibres decrease in size in older subjects ${ }^{14}$ which may be due to preferential atrophy of fast contracting type II muscle fibres. Klitgaard et al. ${ }^{15}$ have reported a $20-26 \%$ drop in velocity at a given torque in elderly men which they linked to a relative increase in type I myosin heavy chain. Thus, the decreased size and possibly decreased percentage of type IIB (fast twitch, predominately glycolytic 
and readily fatigable) fibres may lead to a loss of strength out of proportion to the decline in muscle mass. Frontera et $\mathrm{al}^{6}$ reported that although the strength was related to aging, the differences were smaller if expressed per kilogram of muscle mass suggesting that muscle mass was a major determinant of muscle strength. The progressive decline in number of muscle fibres found in human during aging in the previous study ${ }^{16}$ has not been reproduced in recent animal studies, ${ }^{17}$ where they found no change in muscle number. However, in their recent study, Frontera et al. ${ }^{18}$ reiterate that quantitative loss of muscle strength is a major contributor to the decrease in muscle strength with advancing age, though they also acknowledge that reduction in capillarization could compromise muscle endurance and ultimately the strength.

Electrophysiological ${ }^{19}$ and histochemical ${ }^{20}$ studies show that motoneuron diseases become increasingly more prevalent in older subjects and the number and functional capacity of the muscle motor units declines with age. The remaining motor units are enlarged and tend to have fewer fast twitch fibres. These enlarged motor units partially maintain muscle mass even while strength deteriorates. Although this is true for those more distal muscles, the extent to which more proximal muscles exhibit this loss is less certain. Presumably, the age related denervated-reinervated muscle becomes less efficient, which might explain some of the excessive decline in strength predicted by declining muscle mass. However, Phillips et al..$^{21}$ argue that muscle weakness in the aged is not due to failure of muscle activation and suggests a biochemical cause.

Luff ${ }^{22}$ supposes that the impairment of the aged motoneuron may be related to the integrity of the oxidative metabolic pathways within the cell, given that mitochondrial respiratory chain function is known to be reduced with age. The bioenergetic and biosynthesis demands on the motoneuron are well within the capacity of the young but an increased demand cannot be adequately met by the aged. Changes in the chemical or tissue composition of muscle that occur in malnutrition are independent of changes in mass, however, similar compositional changes accompanying loss of muscle mass during aging is not known. ${ }^{23}$

McCullogh et al. ${ }^{24}$ proposed that some of the wide variability associated with strength: CSA ratio could be due to the biomechanical difference in the lever system.

There are some limitations in our study. First, we did not take into account the dominance of the shoulder in our strength and CSA measurements. Although many studies have found that no significant difference exists between dominant and nondominant normal shoulders ${ }^{25,26}$ others have found that some differences do exist. ${ }^{13}$ The second factor is that we did not consider sex, as a variable, in our data analysis, which has shown to have differences in the measured strength ${ }^{7}$ and cross-sectional area. ${ }^{4}$ As mentioned before, we were not trying to establish normal values but to verify the relationship between aging, strength and CSA, so we believe that our results are valid and reliable. Psychological factors, in that the subjects must be well motivated, to put in maximum efforts in strength testing could have some effect on the measured strength as well. A final limitation could be that there might have been some occult lesions in the tested shoulder which may have been missed in the MRI examination.

\section{CONCLUSION}

Linear regression study showed that combined cross-sectional areas of infraspinatus and teres minor were strongly correlated with aging and strength. The correlation, however, was less strong when comparing with CSA and strength and peak torque/CSA ratio and aging. Thus, while strength losses are partially explained by decrease in muscle mass, there are other factors accountable for the disproportionate loss of strength seen with aging. The mechanism of these other factors and its effect, on aging and muscle mass should be revealed in future longitudinal study.

\section{REFERENCES}

1. Matsen FA, Lippit SB, Sidle JA, Harryman DT. Practical evaluation and management of the shoulder. W B Saunders Company, Philadelphia, pp 1994; 111-150.

2. Maughan RJ, Nimmo MA. The influence of variations in muscle fibre composition of muscle strength and cross-sectional area in untrained males. J Physiol 1984; 351: 299-311.

3. Overend TJ, Cunningham DA, Kramer JF, Lefcoe MS, Paterson DH. Knee extensor and knee flexor strength: cross-sectional area ratios in young and elderly men. J Gerontol 1992; 47: M204-210.

4. Zanetti M, Gerber C, Holder J. Quantitative assessment of the muscles of the rotator cuff with magnetic resonance imaging. Invest Radiol 1998; 33: 163-170.

5. Kallman DA, Plato CC, Tobin JD. The role of muscle loss in the age-related decline of grip strength: Cross-sectional and longitudinal perspectives. J Gerontol 1990; 45: M82-88.

6. Frontera WR, Hughes VA, Lutz KJ et al. A cross-sectional study of muscle strength and mass in 45-to 78-yr-old men and women. J Appl Physiol 1991; 71: 644-650.

7. Kuhlman JR, lannotti JP, Kelly M et al. Isokinetic and isometric measurement of strength of external rotation and abduction of the shoulder. $J$ Bone Joint Surg 1992; 74-A: 1320-1333.

8. Itoi E, Minagawa H, Sato T, Sato K, Tabata S. Isokinetic strength after tears of the supraspinatus tendon. J Bone Joint Surg 1997; 79-B: 77-82.

9. Sapega AA, Kelly MJ. Strength testing of the shoulder. J Shoulder Elbow Surg 1994; 3: 327-345.

10. Sashi R, Terui M, Narita K, Hirano H, Tomura N, Watarai J, Itoi E. Dual 
phased array coils for high-resolution MRI of the shoulder. Radiation Medicine 1997; 15:13-15.

11. Jenp YN, Malanga GA, Growney ES, An KN. Activation of the rotator cuff in generating isometric shoulder torque. Am J Sports Med 1996; 24: $477-485$.

12. Magnusson SP, Gleim GW, Nicholas JA. Subject variability of shoulder abduction strength testing. Am J Sports Med 1990; 18: 349-353.

13. Cahalan TD, Johnson ME, Chao EYS. Shoulder strength analysis using the Cybex II isokinetic dynamometer. Clin Orthop 1991; 271: 249-257.

14. Grimby G, Aniansson A, Zetterberg C, Saltin B. Is there a change in relative muscle fibre composition with age? Clin Physiol 1984; 4: 189194.

15. Klitgaard H, Mantoni M, Schiaffino S, et al. Function, morphology and protein expression of aging skeletal muscle: a cross-sectional study of elderly men with different training backgrounds. Acta Physiol Scand 1990; 140: 41-54.

16. Lexell J, Taylor CC, Sjostrom M. What is the cause of the ageing atrophy? Total number, size and proportion of different fibre types studied in the whole vastus lateralis muscle from 15 -to 83 -year-old men. J Neurol Sci 1988; 84: 275-294.

17. Holloszy JO, Chen M, Cartee GD, Young JC. Skeletal muscle atrophy in old rats: Differential changes in the three fiber types. Mech Ageing Dev 1991; 60: 199-213.

18. Frontera WR, Hughes VA, Fielding RA, et al. Aging of skeletal muscle: a 12-yr longitudinal study. J Appl Physiol 2000; 88: 1321-1326.
19. Campbell MJ, McComas AJ, Petito F. Physiological changes in aging muscles. J Neurol Neurosurg Psychiatry 1973; 36: 174-182.

20. Tomonaga M. Histochemical and ultrastructural changes in senile human skeletal muscle. J Am Geriar Soc 1977; 25: 125-131.

21. Phillips SK, Bruce SA, Newton D, Woldedge RC. The weakness of old age is not due to failure of muscle activation. J Gerontol 1992; 47: M45-49.

22. LuffAR. Age-associated changes in the innervation of muscle fibres and change in the mechanical properties of motor units. Ann N Y Acad Sci 1998; 854: 92-101.

23. Heymsfield SB, McManus C, Smith J, Stevens V, Nixon DW. Anthropometric measurement of muscle mass: revised equations for calculating bone-free arm muscle area. Am J Clin Nutr 1982; 36: 680-690.

24. McCullagh P, Maughan RJ, Watson JS, Weir J. Biomechanical analysis of the knee in relation to measured quadriceps strength and cross-sectional area in man. J Physiol 1983; 346: 60P.

25. Ivey FM, Calhoun JH, Rusche K, Bierschenk J. Isokinetic testing of shoulder strength: Normal values. Arch Phys Med Rehabil 1985; 66: 384-386.

26. Leroux JL, Codine P, Thomas E, et al, Isokinetic evaluation of rotational strength in normal shoulders and shoulders with impingement syndrome. Clin Orthop 1994; 304: 108-115. 